\title{
Study on Mechanism of drainage- anchorage Composite Slope Protection System
}

\author{
Wang Bin ${ }^{1}$, Zang Deji ${ }^{2}$, and Hu lianghao ${ }^{3}$, \\ 134 Hujuguan Road, Nanjing, China, \\ ${ }^{2} 34$ Hujuguan Road, Nanjing, China, \\ ${ }^{3} 34$ Hujuguan Road, Nanjing, China. \\ 1bwang@nhri.cn
}

Key words: anchorage; drainage; composite structure; slope protection

Abstract: For the landslide caused by rainfall, the idea of designing the drainage mechanism with the anchoring system is proposed. The laboratory test has proved that the drainage- anchorage composite structure is feasible. The finite element numerical analysis model is established .The parameters such as the strength and permeability coefficient of the slope soil during the rainfall process are described. The numerical analysis shows that the seepage field and the safety factor change under different conditions. The drainage- anchorage composite system can make the infiltration line down, improve the safety factor. After rainfall, the safety factor can be quickly restored. Therefore, it has a buffer and a rebound effect. It is found that the anchorage angle has a significant effect on the prevention and control effect, and there is an optimal range.

\section{Introduction of drainage- anchorage Composite Structure}

The landslide is a disaster . Its formation factors are complex, can be divided into natural factors and human factors. The main causes include rainfall, snow, water erosion and soaking, earthquakes, artificial excavation and blasting. Some literature shows that the proportion of rainfall-induced landslides accounts for about $90 \%$ of the total ${ }^{[1]}$.

For rainfall-induced landslides, the process of catastrophic formation is: rainfall-soaking-rock-bearing capacity reduction - instability. Therefore, in order to prevent catastrophe, on the one hand, reduce the sliding force and increase the resistance to limit the slippery to continue to develop. On the other hand, the drainage can play a suppression effect, to avoid the formation of a chain reaction

In the prevention of landslides, retaining structures and anchorage structures are often used. In addition, slope drainage is another important aspect,intercepting ditch, underground drainage holes, etc. are used.

In order to combine the two independent systems of resistance and drainage, we propose a drainage- anchorage slope protection system (patent ZL201020556163.5).

Through the reasonable design, the anchor rod can form an ideal drainage channel. The new structure has dual functions of drainage and anchorage. Small improvements can play an unexpected effect.

The first program as shown in Figure 1 (a), the main components include bolts, porous grouting body, bearing plate and so on. The bolt is hollow and the outer annular space of the front part of the bolt is filled with the porous grouting material. The porous grouting material is water permeable. A number of permeate holes are arranged in the hollow anchor wall so that the water in the soil flows into the bolt through the permeable material and flows out of the outlet. Other bolt outside the 
annular space can be filled with mortar as usual. The second program as shown in Figure 1 (b) anchor is solid, the outside filled with porous grouting material, forming a circular permeable channel.

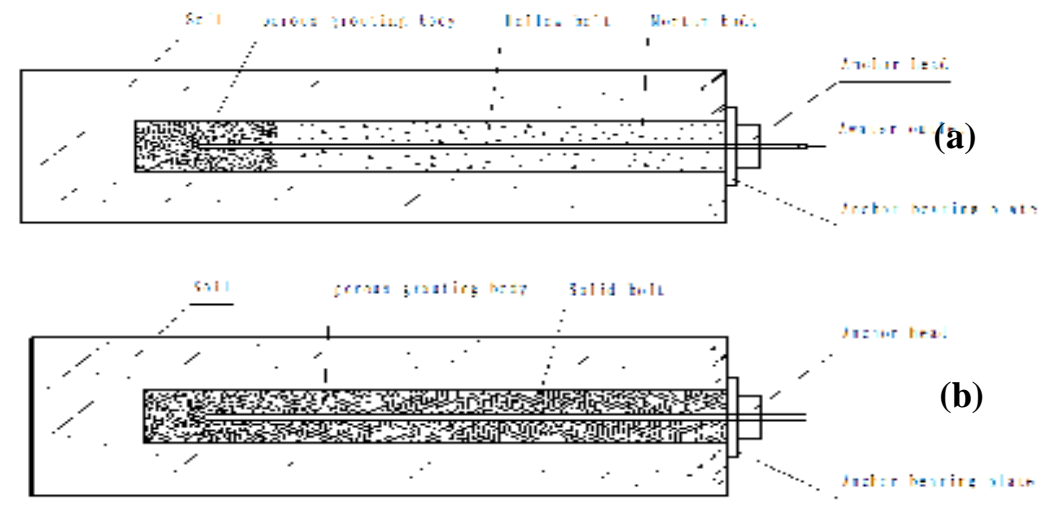

Fig 1. Schematic diagram of drainage- anchorage composite system

One of the keys to building such a system is that the filling material can permeate and carry force. In the world, there are many studies on this kind of cemented material and structure. Since the end of 2070s, the porous concrete has been developed and widely used in the field of pervious subgrade $^{[2],[3]}$. In addition, the German company Elastocoast development of gravel polyurethane for revetment works ${ }^{[4]}$.

\section{Experimental study on drainage- anchorage composite system}

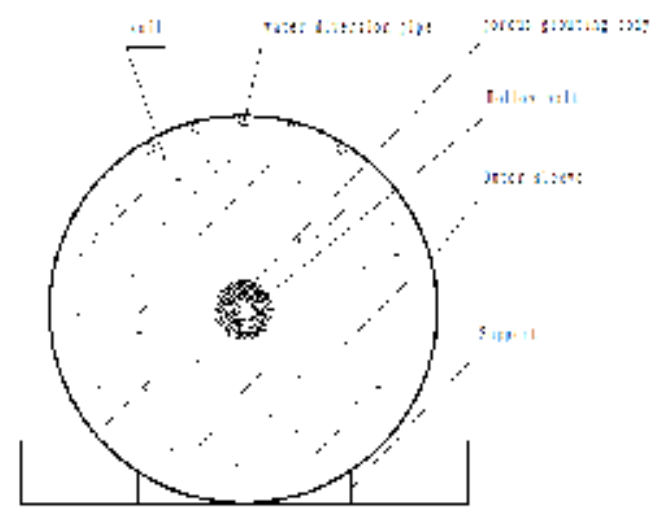

Fig 2. Laboratory test of drainage- anchorage composite structure

In order to explore the feasibility of the permeable anchorage, the laboratory tests were carried out according to the structural test in Fig2.

Hollow FRP bolts were selected for the test. Bolt on the uniform drilling, and each interval of $400 \mathrm{~mm}$ paste strain gauge. The anchor rod is $3 \mathrm{~m}$ long。 Its outer diameter is $22 \mathrm{~mm}$, the inner diameter is $10 \mathrm{~mm}$. The outer ring is covered with $40 \mathrm{~mm}$ thick porous grouting body. After the specimen is molded, it is cured for 2 days. It is buried in the soil after demolding. The mechanical properties of soils are shown in Table 1.The whole was set in a closed cylinder with a diameter of $1.5 \mathrm{~m}$. The pore pressure gauge is used to monitor the water seepage and the horizontal jack is used to load. The data acquisition device is used to collect tension and strain data.

Permeable cement is composed of polyurethane material mixed stone, as shown in Figure 3. The water can penetrate, but the soil particles are difficult to pass through the cement into the permeable hole of the bolt. In order to compare, another group of experiments were carried out with ordinary cement mortar as grouting material. Comparison of two groups of test results are shown in Table 2. 
Table 1 Soil mechanics parameters in the test

\begin{tabular}{llllll}
\hline $\begin{array}{l}\text { cohesion } \\
(\mathrm{kPa})\end{array}$ & $\begin{array}{l}\text { internal } \\
\text { friction angle } \\
\left({ }^{\circ}\right)\end{array}$ & $\begin{array}{l}\text { deformation } \\
\text { modulus } \\
(\mathrm{MPa})\end{array}$ & $\begin{array}{l}\text { gravity } \\
(\mathrm{kPa})\end{array}$ & $\begin{array}{l}\text { Poisson } \\
\text { ratio }\end{array}$ & $\begin{array}{l}\text { Permeability } \\
\text { coefficient } \\
\left(\mathrm{cms}^{-1}\right)\end{array}$ \\
\hline 38.0 & 18.0 & 5.0 & 20.00 & 0.3 & $4 \times 10^{-3}$ \\
\hline
\end{tabular}

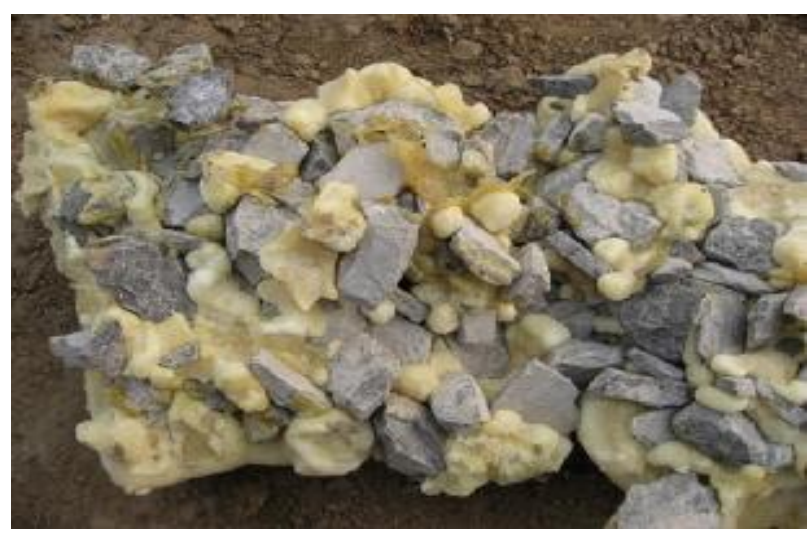

Fig3. Gravel polyurethane porous structure

Table2. Comparison of test results of two kinds of structures

\begin{tabular}{lcccc}
\hline & \multicolumn{2}{c}{ gravel polyurethane } & \multicolumn{2}{c}{ Cement mortar } \\
\hline & Initial time & 6 hours later & Initial time & 6 hours later \\
\hline Moisture content $(\%)$ & $18 \%$ & $13.4 \%$ & $18 \%$ & $17.8 \%$ \\
\hline Anchoring force $(\mathrm{kN})$ & 28 & 30.5 & 25 & 24.7 \\
\hline
\end{tabular}

At the beginning, the water content of the soil was $18 \%$ when the water was fully discharged. The cement mortar anchor can provide $25 \mathrm{kN}$ anchoring force, anchor solid permeable material can provide the anchoring force of $28 \mathrm{kN}$. The surface roughness of the porous grouting material is larger, which leads to the high anchoring force.

After 6 hours, permeable material anchorage surrounding soil moisture decreased to $13.4 \%$, which provide the anchor anchoring force is $30.5 \mathrm{kN}$, increased by $8.9 \%$. While the ordinary cement mortar anchor, the surrounding soil moisture and anchoring force of small changes.

The results show that the new system can play the role of anchorage and drainage.

\section{Numerical analysis of drainage- anchorage composite system}

In order to study the effect and regulation of the drainage- anchorage composite system, the finite element analysis was carried out. This calculation was carried out using the Geostudio 2007 program developed by Geo-Slang, Canada.

In this model, the slope assumes a height of $6 \mathrm{~m}$ and a slope ratio of $1: 1.333$. The slope grid is shown in Fig 4. 


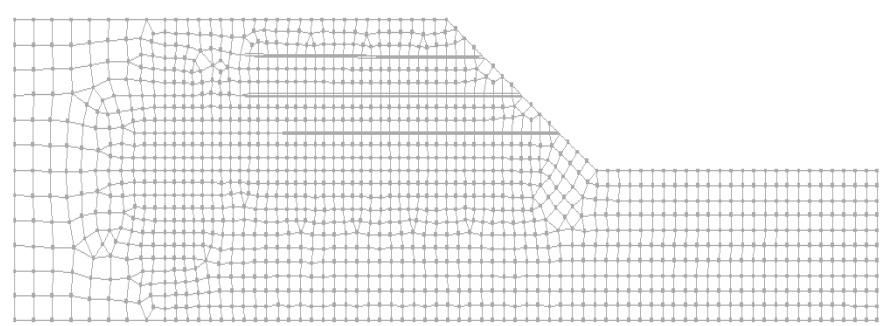

Figure 4. Slope grid division and anchor unit model

(1) Soil mechanics and model

The gravity of the soil is $18 \mathrm{kN} / \mathrm{m}^{3}$, Cohesion (c) was $15 \mathrm{kPa}$, the internal friction angle (Ф) $8^{\circ}$.The soil with better permeability is selected as the object of study, assuming that its saturated permeability coefficient $\mathrm{k}$ is $1.0 \times 10^{-3} \mathrm{~cm} / \mathrm{s}$.

The infiltration of the soil reduces the matrix suction and the shear strength of the unsaturated soil.The relationship between the permeability coefficient and the matrix suction is shown in Fig4. The relationship between the matrix suction and the volume water content is shown in Fig5.

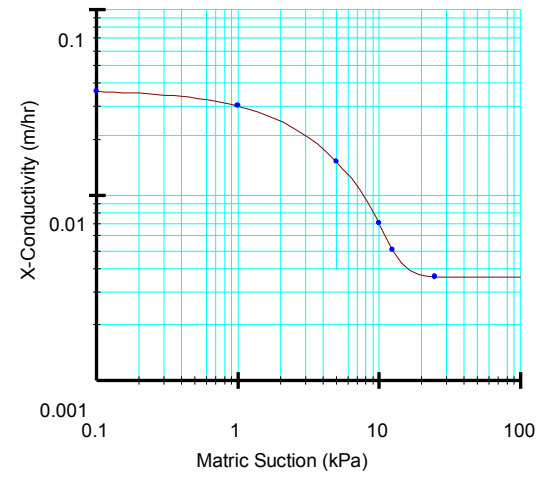

Fig5. Relationship between permeability coefficient and matrix suction

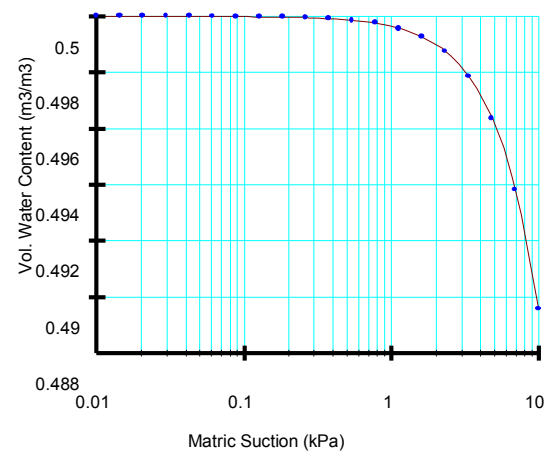

Fig6. Relationship between matrix suction and volume water content

(2) Rainfall and soil seepage model

Slope seepage calculation is carried out using two-dimensional finite element method. The model uses quadrilateral and triangular two types of units, a total of 1380units and 1467 nodes. Assuming a rainfall intensity of $30 \mathrm{~mm} / \mathrm{h}$, the rainfall lasts for $24 \mathrm{~h}$. At the beginning, the groundwater level is $7 \mathrm{~m}$ on the left and $6 \mathrm{~m}$ on the right (flush with the ground). The simulated boundary conditions of rainfall seepage are based on the initial water level boundary simulation. The rainfall infiltration flow boundary is increased on the slope to form a transient model of rainfall simulation. The total flow of water is equal to the amount of rainfall. When the program is running, the relationship between rainfall intensity and permeability is automatically determined.

(3) anchor model

The anchorage system is designed according to the Technical Specification for Geotechnical Anchor (Cable) (CECS22: 2005). The anchoring system is arranged in three layers, the topmost anchor length is $13 \mathrm{~m}$, the anchoring section length is $10 \mathrm{~m}$, the following two layers are $15 \mathrm{~m}$ long and the anchorage length is $12 \mathrm{~m}$. The diameter of the anchor is $15 \mathrm{~cm}$, the bond strength between the anchor and the soil is $100 \mathrm{kPa}$, and the tensile strength of the anchor is $200 \mathrm{kN}$.

(4) Strength criteria

The infiltration of rainwater causes the substrate suction of the unsaturated zone to become low, resulting in a decrease in shear strength. The effect of the negative pore water pressure of the unsaturated soil is taken into account in the stable calculation. According to Fredlund theory, the shear strength intensity equation is: 


$$
s=c^{\prime}+\left(\sigma_{n}-u_{a}\right) \tan \phi^{\prime}+\left(u_{a}-u_{w}\right) \tan \phi^{b}
$$

Where: ua pore pressure, uw-pore water pressure, b- characterization tangential force intensity increases with the suction angle value.

The slope stability calculation is carried out using the limit method. First, the seepage field information obtained from the SEEP / W module is introduced into the slope stability analysis module SLOPE / W, and the slope stability safety factor is calculated.

\section{The main results of numerical analysis}

\section{Changes in seepage field}

In the early stages of rainfall, part of the water flow along the slope, the other part of the rain into the soil. Water infiltration leads to a rapid increase in the surface soil moisture, which makes the infiltration line elevation.

As the rainfall continues, the zero water pressure line(blue line in the figure) rises gradually from the foot. At $8 \mathrm{~h}$, the natural slope is in a saturated state as shown in Fig. 7 (a). Drainage anchor slope has not yet reached saturation, as shown in Figure 7 (b), (c), (d). But the effect of anchoring different inclinations is different.

Compared with the three graphs, it can be seen that the inclination of the bolt (channel) is upward, and the unsaturated soil is larger and the effect is better due to the large displacement. The inclination angle is downward, and the unsaturated area is smaller The effect is relatively poor.
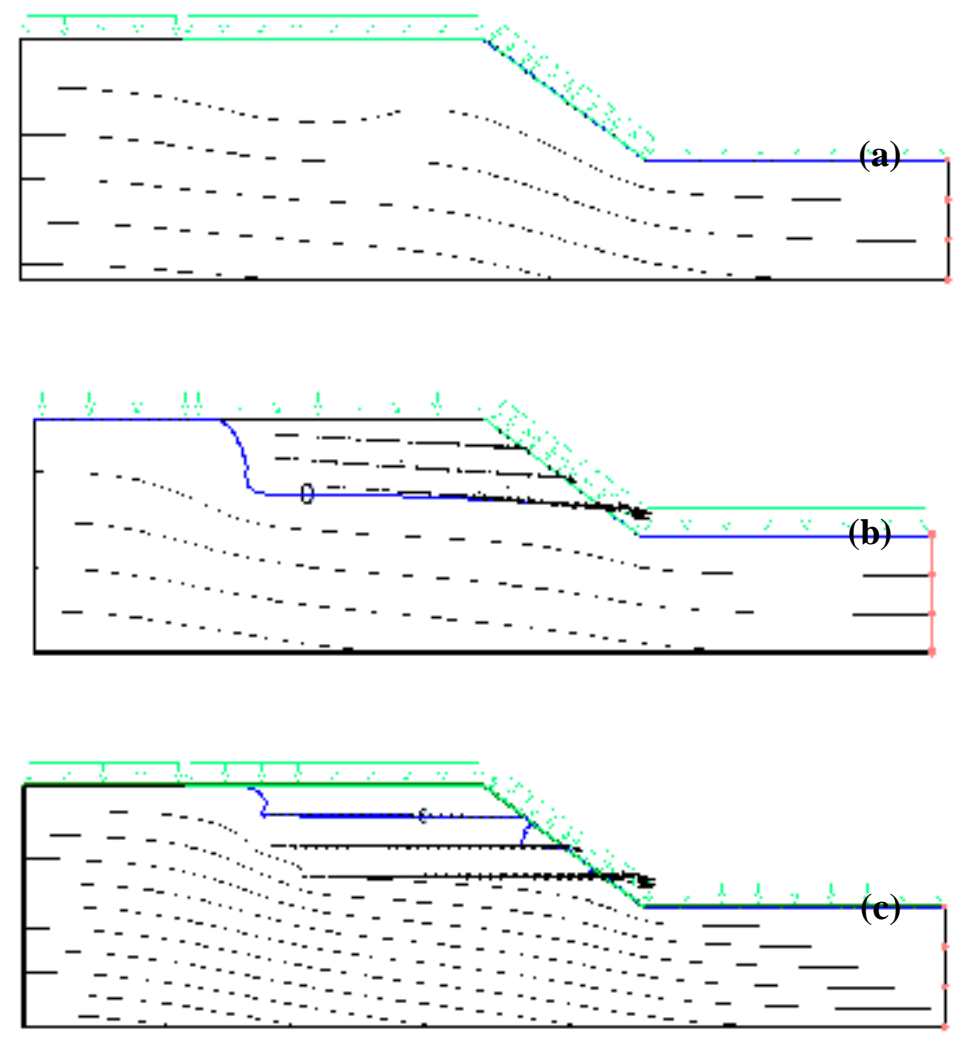

Figure 7. Slope pressure contours for $8 \mathrm{~h}$ after rainfall

Simulated the end of the rain situation, it can be seen that the descending rate of water level in 
anchorage and drainage slope soils is larger than that of natural soil slope. The descending rate is slightly different under different anchorage angle.

\section{Stability analysis}

Figure 8 shows the safety factor in the process of rainfall and suspension. It can be seen that the safety factor of the slope is decreasing with the progress of rainfall, and the safety factor is minimized when the seepage field of the soil is relatively stable. After the end of the rain, with the decline in the water level in the slope, the safety factor gradually increased. The anchor slope is similar to the natural slope.

The contrast curve can be seen: (1)In the case of stability does not meet the requirements, the use of anchorage for natural slope can improve stability.(2) During the rain, the safety factor decreases greatly the in the case of undrained, and The decrease of safety factor is smaller in the case of drainage function. (3)Drainage and anchoring combined, from the static view, slope stability can be improved. From the process of change, for the rainfall caused by the deterioration of the strength of the rock to play a buffer role, and in the rain stop gap, but also play a role in rapid recovery.

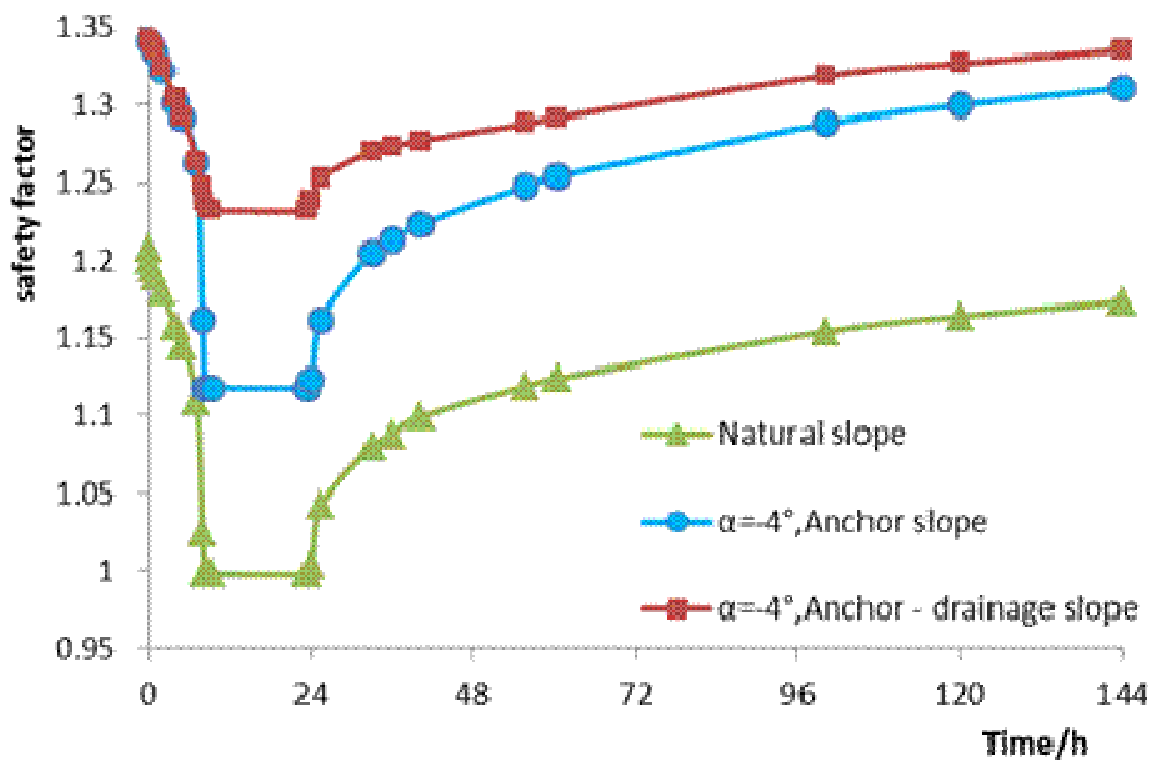

Figure 8. Changes in safety factors during and after rainfall

From the calculation results, the safety factor of anchoring and drainage slope protection is larger than that of simple anchorage slope under the same kind of anchor angle. At the same time, after the end of the rainfall, the safety factor of the anchor-drainage slope is growing faster than the simple anchorage.

\section{Conclusion}

For the landslide caused by rainfall, we design the drainage mechanism in the foundation of the anchoring system to reduce the influence of the rainfall seepage on the soil strength. Laboratory tests show that the choice of porous grouting materials with hollow bolts can be achieved both anchoring and drainage.

Further numerical analysis shows that, due to the increase of the drainage function on the anchorage structure, it can make the infiltration line down and improve the stability of the slope under the rainfall condition. From the development process, during the rain, the drainage function of the rainfall caused by the deterioration of soil strength play a buffer effect, and in the rain stop 
gap, but also play a role in rapid recovery.

Taking into account the drainage and anchorage control effect depends on the combined effect of the two, so the choice of bolt angle is different from the conventional. And there is an optimal range.

To sum up, this method can effectively reduce the pore water pressure, improve the safety factor of slope stability, at the same time strengthen the slope. This method plays an important role in the prevention and control of landslide.

\section{Acknowledgements}

This work was financially supported by the China Natural Science Foundation (51078244).

\section{Reference}

[1] Zhou Chong-bing, LI Dian-yi. Study on the Mechanism of Landslide-induced Landslide and the Method of Disaster Reduction. Advances in Earth Science, 2009 (5): 477-485.

[2] L.lian, Y.zhuge,S.Beechan. The relationship between porosity and strength for porous concrete. Construction and Building Materials25(2011)4294-4298

[3] C.lian,Y.zhuge. Optimun mix design of enhanced permeable concrete-Anexperimental investigation. Construction and Building Materials24(2010)2664-2671

[4] Dehua Gu. Hydraulic Properties of PUR-Revements compared to those of open stone as phalt Revements [ D]. Delft: Delft University of Technology.2007 